\title{
A Step-By-Step Tracking Program for a String of Photovoltaic Modules
}

\author{
N. I. Tatu ${ }^{1}$, C. Alexandru ${ }^{1}$, V. E. Dombi ${ }^{1}$ \\ ${ }^{1}$ Department of Renewable Energy Systems and Recycling \\ Transilvania University of Braşov \\ B-dul Eroilor, 29, 500036 Braşov (România) \\ Phone/Fax number: +0040 268 412921, e-mail: nicoleta-irina.tatu@unitbv.ro, calex@unitbv.ro, veronica.dombi@unitbv.ro
}

\begin{abstract}
The objective of this paper is to create a step-bystep tracking program which assures an increased energetic efficiency for a string of photovoltaic (PV) modules. This is achieved through various calculations, having as parameters: the solar angles, solar time, day of the year and turbidity factor, following to capture the maximum solar radiation, but with a small angular domain of the daily angle. For a motion law with high precision, the year is split into 8 time intervals and for each one it is found the optimum fixed elevation angle with the according daily angle field.
\end{abstract}

\section{Key words}

Photovoltaic, solar radiation, tracking, step-by-step, string.

\section{Introduction}

In the domain of producing electric energy, the fossil fuels can be successfully replaced with renewable energies (Sun, wind, water). The solar energy can be converted into thermal or electric energy (photovoltaic systems). The PV systems have no emission of pollutant gasses into the atmosphere and the energy provided can be used to supply remote areas or fed into the grid. In order to expand their usage, researchers try to improve their yield, conversion and energetic efficiency keeping a simple design and still being cost effective [1].

The tracking of PV systems can increase the energetic efficiency with 50\% [2] more than fixed systems. This improvement is achieved through tracking mechanisms [3]-[5] designed to follow the Sun on the sky on the basis of certain control techniques (closed or opened loop).

In closed loop control systems, photo-sensors are used to determine Sun`s positions on the sky sending electrical signals to the motor source, thus actuating the motor to track the Sun. However, in unstable weather conditions (heavy rain or cloudy sky), it will be very difficult to find the real position of the Sun, generating errors.
In the opened loop control systems, mathematical algorithms [6]-[8] or programs are regarded as motion laws and used as input parameters for the motor sources. These algorithms are defined as functions of solar angles and can be computed for any given geographical area with specific formulas (case study: Braşov, România).

Considering the above mentioned conditions, the paper presents a tracking program designed to increase the energetic efficiency of a string of PV modules. The year is split into time intervals called seasons, and for each one there are computed the optimum angles for which is received the maximum quantity of solar radiation.

\section{Calculation of optimum angles}

In order to receive as much solar radiation as possible, the sunrays must always fall normal to the system`s plane. This is achieved through continuous tracking (ideal case), but, due to high operating time of the motor sources, necessity of performing large transmission ratios and to system behaviour under the influence of external non-stationary elements (ex. wind), the motion law is performed step-by-step (with an equal number of steps every hour) [9].

The motion law was designed to ensure the optimum positioning of the PV system relative to the Sun`s position on the sky, so that the received solar radiation is very close to the ideal case.

The PV system is orientated according to two angles: module tilt angle, $\gamma^{*}$, which is kept at a fixed value throughout the duration of a season or the entire year and the daily angle, $\beta^{*}$, around which the daily motion is performed. In turn, these depend on the following: the angles determining Sun`s position on the sky dome: latitude $\varphi$, declination $\delta$, hour angle $\omega$, altitude $\alpha$ [10]. From these angles were determined the angles used for the sunray orientation: elevation angle, $\gamma$ and daily angle, $\beta$ (fig. 1) [11]. 


$$
\begin{gathered}
\sin \beta=\cos \delta \cdot \sin \omega \\
\sin \gamma=\frac{\cos \delta \cdot \cos \omega \cdot \sin \varphi-\sin \delta \cdot \cos \varphi}{\cos \beta}
\end{gathered}
$$

To find the adequate step-by-step tracking program in the premise of the previously specified criterion, the optimum angles must be found through a series of combinatorial calculations of $\gamma^{*}$ and $\beta^{*}$.

The optimum values for this pair of angles are found at the point where the tracking efficiency is highest, but with a minimum angular field of the daily angle in order to keep the energy consumption during tracking at minimum. The tracking efficiency is the percentage ratio between the produced and available energy, which are computed by integrating the solar radiation curves.

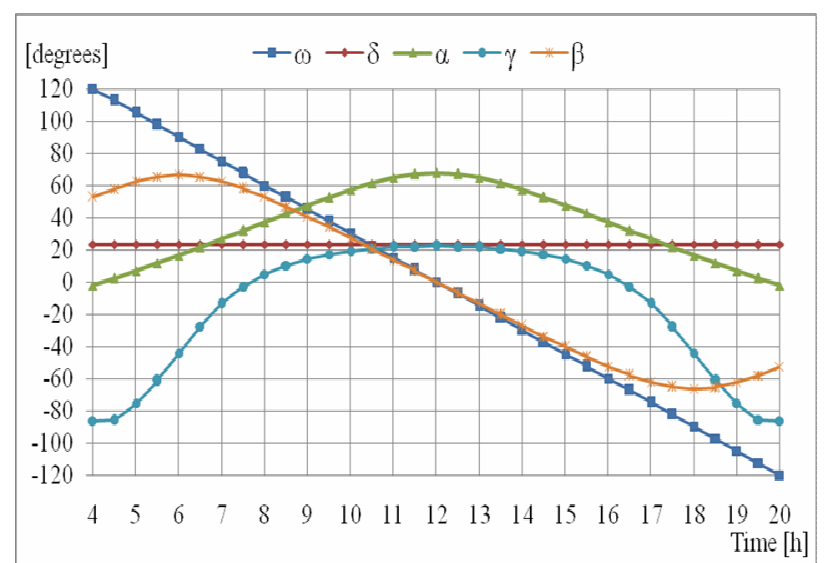

a)

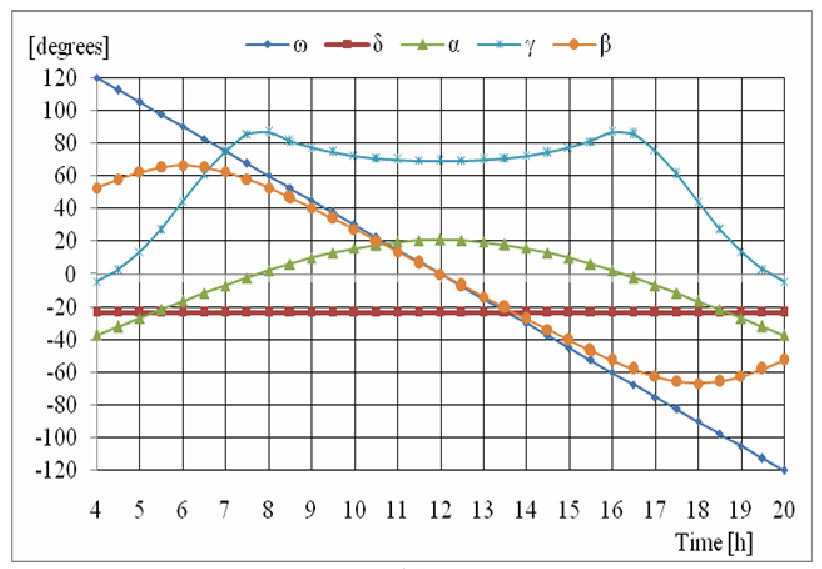

b)

Fig 1. Variation of solar angles at a) summer solstice; b) winter solstice.

The solar radiation is influenced by a series of parameters specific for each geographical area (coordinates, season, hour), climatic conditions and parameters (clouds, rain, turbidity factor $-T_{R}[12]$ ) and degree of pollution. In order to estimate the direct solar radiation $(\mathrm{R})$ for Braşov region it was used the following mathematical model, where $\mathrm{N}$ represents the day of the year:

$$
R=1367 \cdot(1+0.0334 \cdot \cos x) \cdot e^{\frac{-T_{R}}{0.9+9.4 \cdot \sin \alpha}}
$$

$$
x=0.9856 \cdot N-2.72^{0}
$$

The incident solar radiation $\left(\mathrm{R}^{*}\right)$ is given by the following formula, with $v$ as incidence angle (between sunray and normal to the module):

$$
R^{*}=R \cdot \cos v
$$

For a PV system to capture the maximum amount of solar radiation it has to maintain the incidence angle at minimum (zero in the ideal case, continuous movement). At its turn the incidence angle is computed using the angles giving the sunray orientation $(\gamma$ and $\beta)$ and the PV angles $\left(\gamma^{*}\right.$ and $\left.\beta^{*}\right)$.

$$
\begin{aligned}
\cos v & =\cos \beta \cdot \cos \beta^{*} \cdot \cos \left(\gamma-\gamma^{*}\right) \\
& +\sin \beta \cdot \sin \beta^{*}
\end{aligned}
$$

To enhance the precision of the motion law, the year was split into 8 seasons depending on the declination angle, $\delta$ (fig. 2). Within each season were chosen the most important three days: first, middle and last day as seen in Table 1 (for example, 310 represents 6 November 2010). For each day were computed the direct and incident solar radiation and the corresponding diagrams.

Table 1. Seasons

\begin{tabular}{|c|c|c|c|}
\hline Season & First day & Middle day & Last day \\
\hline I & 310 & 355 & 35 \\
\hline II & 36 & 51 & 67 \\
\hline III & 68 & 81 & 93 \\
\hline IV & 94 & 106 & 118 \\
\hline V & 119 & 172 & 226 \\
\hline VI & 227 & 238 & 250 \\
\hline VII & 251 & 265 & 278 \\
\hline VIII & 279 & 294 & 309 \\
\hline
\end{tabular}

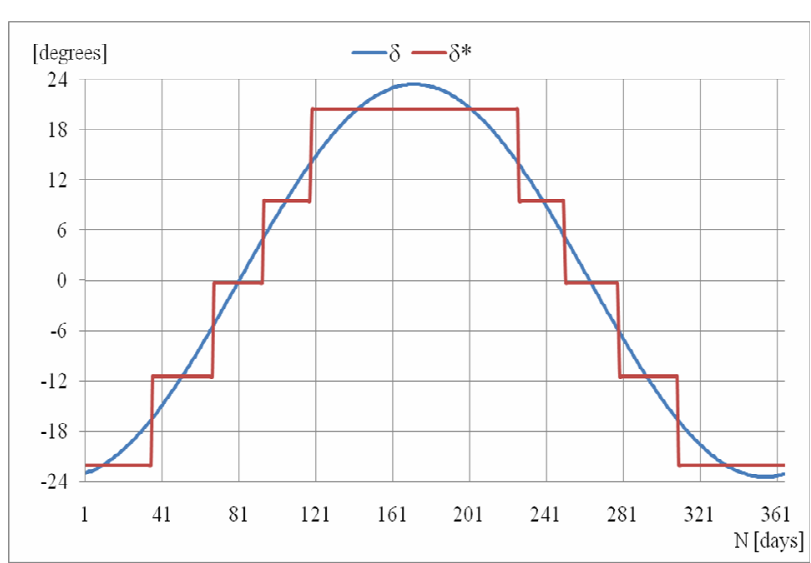

Fig 2. The 8 seasons of the year based on the solar declination angle

The motion law steps are chosen according to the angle $\beta$ curve of each season`s middle day (fig. 3). Each step is performed hourly having the actuating time of one 
minute. When the $\gamma^{*}$ is kept fixed throughout the whole year, the motion law is chosen according to angle $\beta$ corresponding to an equinox.

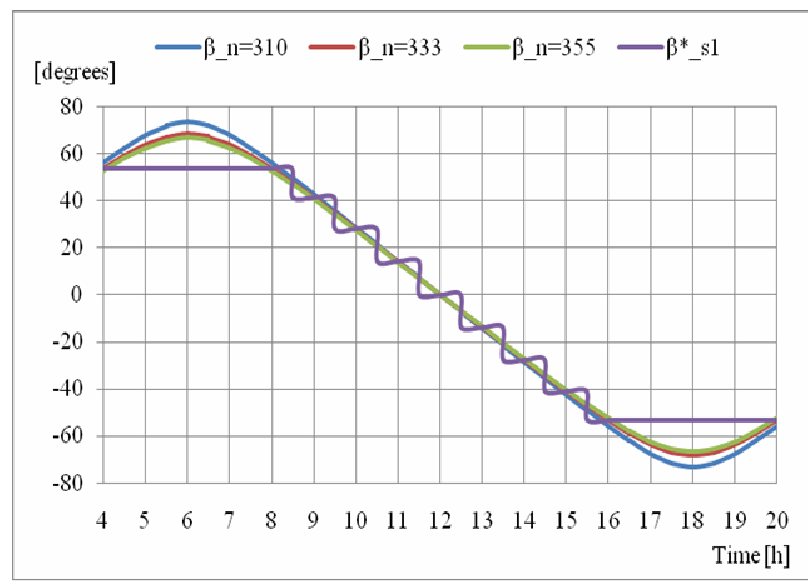

a)

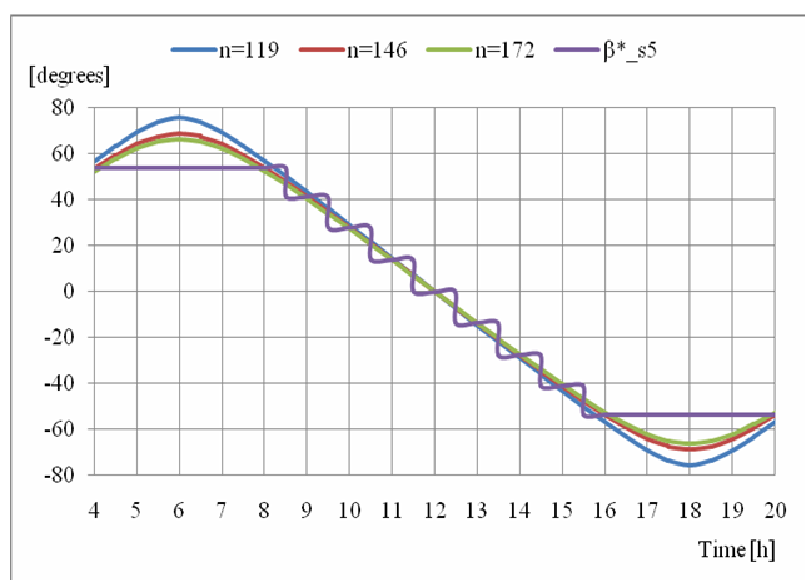

b)

Fig 3. The motion law for: a) season 1 (includes winter solstice); b) season 5 (includes summer solstice).

The number of steps varies according to season from 16 steps in season 5 (summer season) to 8 in season 1 (winter season), plus the step taken to return the system to its previous position. Taking into consideration that in the morning the amount of solar radiation is small, the number of steps was reduced to 8 for each season.

Afterwards, for the combinatorial calculations, various values were attributed to the daily and elevation angles as follows: $\beta^{*}$ varies in the intervals $\left[+15^{0} ;-15^{0}\right],\left[+30^{0}\right.$; $\left.30^{0}\right],\left[+45^{0} ;-45^{0}\right],\left[+60^{0} ;-60^{0}\right],\left[+75^{0} ;-75^{0}\right],\left[+90^{0} ;-90^{0}\right]$ and the value $0^{0} ; \gamma^{*}$ takes fixed values within the interval $\left[0^{0} ; 90^{\circ}\right]$. All simulations were performed in the premises of clear sky.

\section{Simulation results and final conclusions}

In this section of the paper were determined the fixed values of the elevation angle $\gamma^{*}$, for each season, simultaneous with the correspondent angular domain of the daily angle $\beta^{*}$. For each pair of angles the quantity of the incident solar radiation is close to the ideal case (continuous).
Furthermore, it was established a specific pair of angles used to track the string of PV modules in 8 steps each performed in 1 minute.

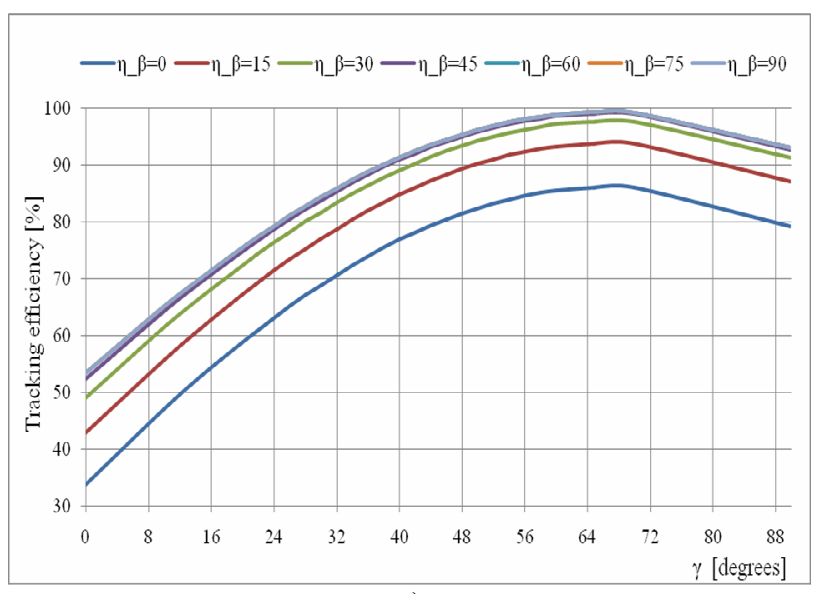

a)

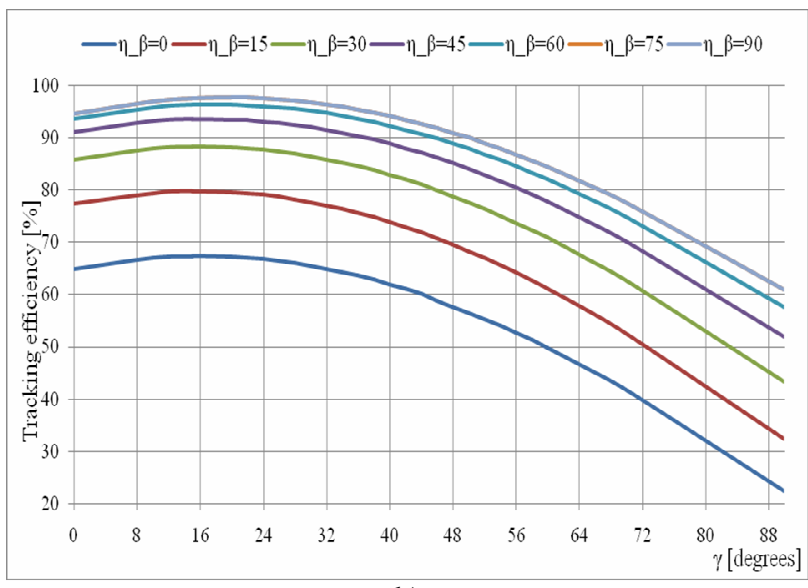

b)

Fig 4. Optimum value of $\gamma^{*}$ in: a) season $1\left(\gamma^{*}=65^{0}\right)$; b) season $5\left(\gamma^{*}=20^{0}\right)$, according to the tracking efficiencies established.

From the energies correspondent to all pair angles $\gamma^{*}$ and $\beta^{*}$ of the most important days belonging to each season, were computed the energies of every season average day. The tracking efficiencies, calculated from the previous mentioned average energies, determined the optimum elevation angle $\gamma^{*}$, found at the highest tracking efficiency (for example, in fig. 4 are presented the tracking efficiencies for seasons 1 and 5).

In order to determine the optimum angular domains of $\beta^{*}$, there were recalculated the direct and incident radiations, energies and tracking efficiencies for the three most important days of all 8 seasons with their corresponding diagrams using the found optimum values of the elevation angle $\gamma^{*}$.

Because the energetic intake (efficiency) from angular domains cases: $\beta^{*} \in\left[+75^{\circ} ;-75^{\circ}\right]$ and $\beta^{*} \in\left[+90^{\circ} ;-90^{\circ}\right]$ is very small comparative with $\beta^{*} \in\left[+60^{0} ;-60^{0}\right]$, the last was chosen as optimum for the daily angle $\beta^{*}$ in all seasons (fig. 5 - tracking efficiencies for season 5 with $\gamma^{*}=65^{0}$ and season 1 with $\gamma^{*}=20^{\circ}$ as fixed values). Although the domain is the same, the motion steps are different in every season. 


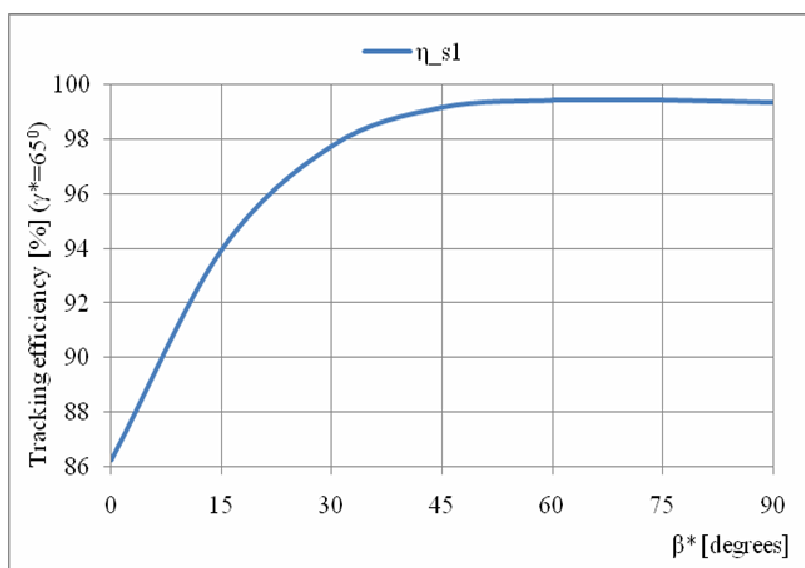

a)

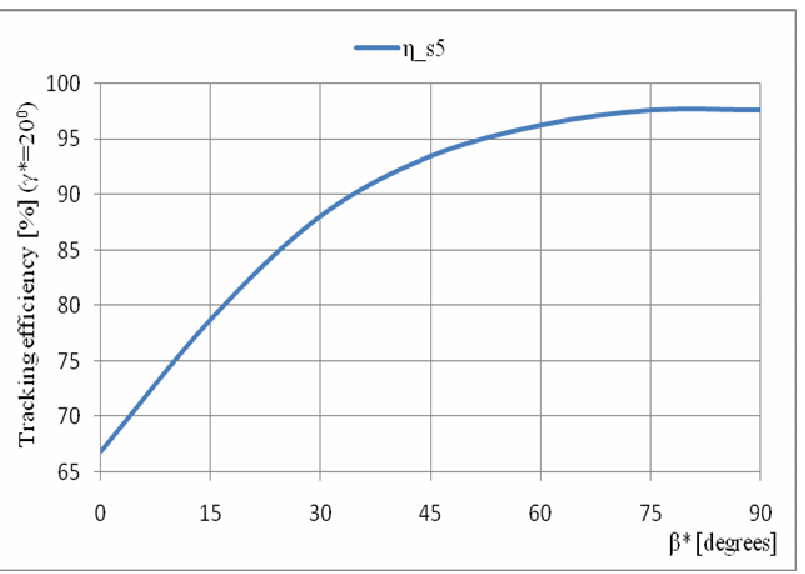

b)

Fig 5. Determination of $\beta^{*}$ angular domain in: a) season 1 ; b) season 5 .

To determine the annual optimum pair of angles, the same steps were followed in performing the calculations for all 24 days in the year with the specification that the motion law of $\beta^{*}$ is the same throughout the year. So, the final values are presented in table 2 , where $\gamma^{*}$ _s and $\beta^{*} \_s$ are the values of the motion laws performed every season, $\gamma^{*} \_y$ and $\beta^{*} \_y$ the values for the same motion law throughout the year.

Table 2. Values of the angles $\gamma^{*}$ and $\beta^{*}$

\begin{tabular}{|c|c|c|c|c|}
\hline Seasons & $\gamma^{*} \_s$ & $\beta^{*} \_s$ & $\gamma^{*} \_\mathrm{y}$ & $\beta^{*} \_\mathrm{y}$ \\
\hline I & $65^{0}$ & \multirow{8}{*}{$\begin{array}{l}8 \\
0 \\
1 \\
\therefore \\
0 \\
0 \\
+\end{array}$} & \multirow{8}{*}{ 讨 } & \multirow{8}{*}{$\begin{array}{l}5 \\
8 \\
1 \\
\therefore \\
8 \\
0 \\
\pm\end{array}$} \\
\hline II & $58^{0}$ & & & \\
\hline III & $46^{0}$ & & & \\
\hline IV & $34^{0}$ & & & \\
\hline $\mathrm{V}$ & $20^{\circ}$ & & & \\
\hline VI & $34^{0}$ & & & \\
\hline VII & $46^{0}$ & & & \\
\hline VIII & $58^{0}$ & & & \\
\hline
\end{tabular}

The optimum values of the elevation angle $\gamma^{*}$ and daily angle $\beta^{*}$ will be used in a comparative study between mono-axis and bi-axis tracking programs for a string of PV modules. The survey is presented in detail in another paper participating at the International Conference on
Renewable Energies and Power Quality, ICREPQ 2011 ("Mono-axis vs Bi-axis Tracking for a String of Photovoltaic Modules").

The future research will take into consideration the diffuse radiation, the variable atmospheric conditions and the temperature of the PV module.

\section{Acknowledgement}

This paper is supported by the Sectoral Operational Programme Human Resources Development (SOP HRD), financed from the European Social Fund and by the Romanian Government under the contract number POSDRU/88/1.5/S/59321.

\section{References (selection)}

[1] A. Hoffmann, H. Frindt, M. Spinnler, J. Wolf, T. Sattelmayer, T. Hartkopf, A Systematic Study on Potentials of PV Tracking Modes, Proceedings of the 23rd European Photovoltaic Solar Energy Conference, Valencia, 2008, pp. 3378-3383, (WIP-Renewable Energies \& European Commission).

[2] T. Huld, T. Cebecauer, M. \& E. D. Dunlop, Analysis of One-Axis Tracking Strategies for PV Systems in Europe, Progress in Photovoltaics: Research and Applications, 18, 2010, p. 183-194.

[3] L. Guo, P. Curtis, A. Barendregt, A. Surillo, Design and Implementation of a Sun Tracking Solar Power System, Proceedings of the ASEE Annual Conference \& Exposition, Austin, June 2009, ID 10308, pp. 1-11 (American Society for Engineering Education - ASEE).

[4] C. Alexandru, C. Pozna, Simulation of a Dual-Axis Solar Tracker for Improving the Performance of a Photovoltaic Panel, Proceedings of the Institution of Mechanical Engineers, Part A: Journal of Power and Energy, vol. 224, nr. 6/2010, p. 797-811.

[5] B. Mokhtari, A. Ameur, L. Mokrani, B. Azoui, M.F. Benkhoris, DTC Applied to Optimize Solar Panel Efficiency, Proceedings of the 35th Annual Conference of the IEEE Industrial Electronics Society - IECON, Porto, 2009, pp. 11221127.

[6] R. Parkin, Solar Angles Revisited Using a General Vector Approach, Solar Energy 84, 2010, pp. 912-916.

[7] K.K. Chong, C.W. Wong, General Formula for On-Axis Tracking System and Its Application in Improving Tracking Accuracy of Solar Collector, Solar Energy 83, 2009, pp. 298305.

[8] E.D. Mehleri, P.L. Zervas, H. Sarimveis, J.A. Palyvos \& N.C. Markatos, Determination of the Optimal Tilt Angle and Orientation for Solar Photovoltaic Arrays, Renewable Energy 35, 2010, pp. 2468-2475.

[9] I. N. Tatu, C. Alexandru, Tracking Mechanism for a Group of Photovoltaic Modules, 25th European Photovoltaic Solar Energy Conference and Exhibition, Valencia, Spain, 2010, pp. 4424-4428 (WIP-Renewable Energies \& European Commission).

[10] M. Meliß, Regenerative Energiequellen - Praktikum, Springer-Verlag (1997).

[11] B. Burduhos, I. Vişa, D. Diaconescu, R. Săulescu, Novel Orientation Step-Program of a Pseudo-Equatorially Tracked PV Panel, 24th European Photovoltaic Solar Energy Conference and Exhibition, Hamburg, Germany, 2009, (WIP-Renewable Energies \& European Commission).

[12] L. Coste, E. Eftimie, Linke Turbidity Modelling for Braşov Urban Area, International Conference on Renewable Energies and Power Quality, Granada, Spania, 2010. 